\title{
New Approach of Starch and Chitosan Films as Biodegradable Mulching
}

\author{
Brandelero, R. P. H.;* Alfaro, A. T.; Marques, P. T.; Brandelero, E. M.
}

Rev. Virtual Quim., 2019, 11 (3), 686-698. Data de publicação na Web: 25 de junho de 2019

http://rvq.sbq.org.br

\section{Nova Abordagem dos Filmes de Amido e Quitosana como Mulching Biodegradável}

Resumo: Os polímeros amido e quitosana podem resultar em filmes biodegradáveis para reduzir a poluição por plástico no ambiente. A adição de quitosana pode melhorar as propriedades dos filmes de amido, bem como a adição de pigmentos auxilia no controle do crescimento de plantas invasoras. $O$ objetivo do presente trabalho foi analisar o comportamento de filmes de amido/quitosana adicionados de pigmentos quando aplicados como mulching. Os valores de resistência a tensão na ruptura não variaram com a formulação, enquanto filmes adicionados com pigmentos foram mais flexíveis. A adição de quitosana reduziu em duas vezes a solubilidade dos filmes quando comparados aos filmes só de amido. Os filmes em contato com o solo apresentaram redução nas propriedades mecânicas, alterações no espectro no infravermelho e nas micrografias, no entanto os filmes não apresentaram fraturas visíveis por 45 dias. Os filmes de amido/quitosana serviram como mulching biodegradável.

Palavras-chave: Biopolímeros; filmes finos; mulching biodegradável; caracterização.

\begin{abstract}
Natural polymers, such as starch and chitosan, can to result in biodegradable films to reduce plastic pollution. The addition of chitosan can improve the properties of starch films to use in agriculture, well as the addition of pigments that to help in the controlling the growth of invasive plants. The aim of this study was to analyze the behavior of mulch obtained from the starch-chitosan films with the addition of inorganic pigments. The tensile strength of the films at ruptures did not vary with the formulation, and the films with pigments were more flexible. The addition of chitosan achieved a two-fold reduction in film solubility in comparison with that of films composed of only starch. When in contact with the soil, the films exhibited a decrease in properties and changes in infrared spectrum and micrographs; however, the films showed no visible cracks for 45 days. Thus, the starch-chitosan films can effectively serve as biodegradable mulch.
\end{abstract}

Keywords: Biopolymer; thin films; biodegradable mulching; characterization.

\footnotetext{
* Federal University of Technology - Paraná, Department of Agronomy, Campus Dois Vizinhos, CEP 85660-000, Dois Vizinhos-PR, Brazil.

Mrenatapherrera@gmail.com

DOI: $\underline{10.21577 / 1984-6835.20190051}$
} 


\section{New Approach of Starch and Chitosan Films as Biodegradable Mulching}

\section{Renata Paula Herrera Brandelero, ${ }^{\mathrm{a}, *}$ Alexandre Trindade Alfaro, ${ }^{\mathrm{b}}$ Patrícia Texeira Marques, ${ }^{\mathrm{c}}$ Evandro Martin Brandelero ${ }^{\mathrm{a}}$}

${ }^{a}$ Federal University of Technology - Paraná, Department of Agronomy, Campus Dois Vizinhos, CEP 85660-000, Dois Vizinhos-PR, Brazil.

${ }^{b}$ Federal University of Technology - Paraná, Department of Foods, Campus Francisco Beltrão, Francisco Beltrão, CEP 85601-000, Francisco Beltrão-PR, Brazil.

${ }^{\mathrm{C}}$ Federal University of Technology - Paraná, Department of Chemistry, Campus Pato Branco, CEP 85503-390, Pato Branco-PR, Brazil.

* renatapherrera@gmail.com

1. Introduction

2. Materials and Method

2.1. Material

2.2. Development of the films

2.3. Application of the films on soil

2.4. Spectroscopy of Infrared (FTIR)

2.5. Scanning Electron Microscopy

2.6. Isotherms of the sorption

2.7. Water Vapor Permeability (WVP)

2.8. Solubility of the films

2.9. Mechanical property

\section{Results and Discussion}

3.1. Isotherm of sorption

3.2. Spectroscopy of the films for FTIR

3.3. Microscopy of the films

3.4. Thickness, mechanical properties, permeability to water steam and solubility

\section{Conclusion}

1. Introduction
Natural polymers, such as starch and chitosan, by casting or extrusion in the presence of a plasticizer or in blends with other polymers can to result in biodegradable 
films for different applications. ${ }^{1,2}$ In agriculture, many types of plastic materials are utilized, such as bags of seedlings and films to cover the soil, named as mulch, if these plastic materials were biodegradables can contribute to the reduction of environmental problems caused by the accumulation of plastic residues in nature, helping too in the reduction of the costs involved with the recycling and collection of mulch in cultivation areas.

Chitosan is used as nitrogen fertilizer and in the phytoremediation of soli. ${ }^{3}$ The mixture of starch and chitosan results in a film of lower solubility. The reduction in the solubility is essential for films used in agriculture owing to their intense contact with irrigation water. According to studies published in the scientific literature, the mixture of chitosan and starch results in films with more rigidity and less solubility in comparison with films prepared with $100 \%$ starch. ${ }^{4-6}$

The incorporation of a crosslinking agent in the polymer films, i.e., starch, can improve the properties of the films. Citric acid is considered a safe crosslinker as it is biodegradable; it can realize linkages between its carboxylate groups and the hydroxyl groups of starch. In the previous studies, ${ }^{7,8}$ the addition of $5 \%$ citric acid to starch films reduced their solubility and swelling, while increasing their mechanical resistance. Additionally, Menzel et al. ${ }^{9}$ confirmed that citric acid can establish linkages with starch in both high $\left(150 \quad{ }^{\circ} \mathrm{C}\right)$ and low $(70 \mathrm{C})$ temperatures.

The blend between starch and chitosan results in films of low hydrophilicity, which can be attributed to the formation of ester bonds and the association between the hydroxylgroup of the biopolymers, thereby reducing the availability of sites for linkage with water. The reduction in the hydrophilicity of biopolymer films is important because of the effect of water sorption, which reduces the mechanical resistance of the films and increases their permeability to water vapor. Therefore, the starch-chitosan films are much more stable to the variations in the surrounding moisture in comparison with starch films. The addition of citric acid to the starch can improve the characteristics of the films; the blends between starch/citric acid and chitosan result in the reduction of the hydrophilicity and solubility of the films, thereby reforming the mechanical properties.

The plastic films used to cover the soil are called mulches, and are used to avoid the loss of moisture, control the soil temperature, increase the sanity of the culture, and control the growth of invasive plants. ${ }^{10}$ The applicability of mulch films is greater for the growth of vegetables and flowers, such as lettuce, which is a vegetable of short cycle that is ready for consumption within a few days; therefore, biodegradable materials can be investigated for use as a substitute to the polyethylene materials in the production of these vegetables.

Films for agriculture require the addition of pigments to block solar rays and help control the germination of invading plants. The color of the plastic helps to control the soil temperature in different seasons, as well as influence the growth of the plants. The pigments can alter the properties of the films or the duration of the films in the field; hence, considering their effect on the properties of the films is essential. ${ }^{11}$ Titanium oxide is used as a white pigment in many applications. It has a wide range of applications, including solar protectors and food coloring, as it is harmless to the environment. The oxide from the iron, extracted from a mineral magnetite, is used for pigment blacks.

The addition of pigments to films is necessary to block the solar radiation; however, the effect of pigments on the properties of films remains to be analyzed. Therefore, this study aims to evaluate the effects of the addition of citric acid and inorganic pigments on the properties of films obtained by blends of starch with chitosan, well as to analyze the behavior and properties of films when in contact with the soil for 45 days. 


\section{Materials and Method}

\subsection{Materials}

The starch was obtained from mark Pinduca (Paraná, Brazil), with $22 \%$ amylose and a purity of $99.5 \%$. Chitosan was acquired from Sigma Aldrich (USA) with a molar medium mass and 75-85\% deacetylation. Glycerol with $98 \%$ purity and anhydrous citric acid were obtained from Synth (Diadema, Brazil). The utilized pigments comprised 30$60 \%$ ferric oxide commercially obtained from Lanxess (Brazil). They were selected based on their solubility in a polymeric solution. The white pigment used was a titanium dioxide solution with $10 \%$ calcium carbonate used as the dispersant.

\subsection{Development of the films}

The films were obtained through casting. The starch films with chitosan and citric acid (FTSCTICH) were prepared with $2.4 \mathrm{~g}$ of chitosan (33\% of the total polymer mass), 4.8 g of revoking starch (66\% of the total polymer mass), and $0.24 \mathrm{~g}$ of citric acid ( $5 \%$ of the total starch mass). Chitosan was solubilized in 60 $\mathrm{mL}$ of citric acid with a concentration of $2 \%$ $(\mathrm{v} / \mathrm{v})$. The starch, citric acid, and glycerol were added to $120 \mathrm{~mL}$ of distilled water and the mixture was heated at $75^{\circ} \mathrm{C}$. The chitosan and starch solutions were mixed, and the $\mathrm{pH}$ value was determined as 4.0. The black film (FTSCITCHB) and white film (FTSCITCHW) were obtained by adding $1 \mathrm{~mL}$ of the appropriate pigment to the polymer solution.

Starch films with citric acid (FTSCIT) were produced by adding $7.2 \mathrm{~g}$ of starch (100\% of the total polymer mass), $1.4 \mathrm{~g}$ of glycerol, and $0.36 \mathrm{~g}$ of citric acid ( $5 \%$ of the total polymer mass). The starch, citric acid, and glycerol (20\% of the total polymer mass) were added to $200 \mathrm{~mL}$ of the solution (FTSCIT films), while only glycerol was added to the FTS films. The films were all then heated to $75^{\circ} \mathrm{C}$.

The solutions of the films dried on $25 \times 25$ $\mathrm{cm}$-acrylic plates in a drying oven for $14 \mathrm{~h}$ at $50{ }^{\circ} \mathrm{C}$ to yield $12.12 \mathrm{mg}$ of solids $/ \mathrm{cm}^{2}$.

\subsection{Application of the films on soil}

The films were applied on the CF4 soil, with a pH of 5.50, organic matter content of 34.45 $\mathrm{g} / \mathrm{dm}^{3}$, phosphorus content of $117.56 \mathrm{~g} / \mathrm{dm}^{3}$, potassium content of $0.25 \mathrm{cmol} / \mathrm{dm}^{3}$, calcium content of $6.90 \mathrm{cmol} / \mathrm{dm}^{3}$, magnesium content of $3.30 \mathrm{cmol} / \mathrm{dm}^{3}$, and a base saturation of $66.14 \%$. The soil was placed into $53 \times 17 \times 15 \mathrm{~cm}$-rectangular vases. The pots were covered with starch/chitosan films, being those drilled for the planting of the lettuce seedlings, the vases were maintained in a greenhouse and were irrigated by dropping. The films remained on the soil for 45 days before being withdrawn for analyses. The middle temperature inside the greenhouse was of $22.16^{\circ} \mathrm{C}$. Figure 1 presents the general appearance of the white (FTSCITCHW) and black (FTSCITCHB) biodegradable films on the first day, as well as when the films were collected for analysis after about 45 days (after harvest). The films FNbio-white and FNbio-black, which are films of polyethylene, are traditionally used as mulching. The biodegradable films after harvest were washed, dried, and bodies of proofs were obtained for analysis. 


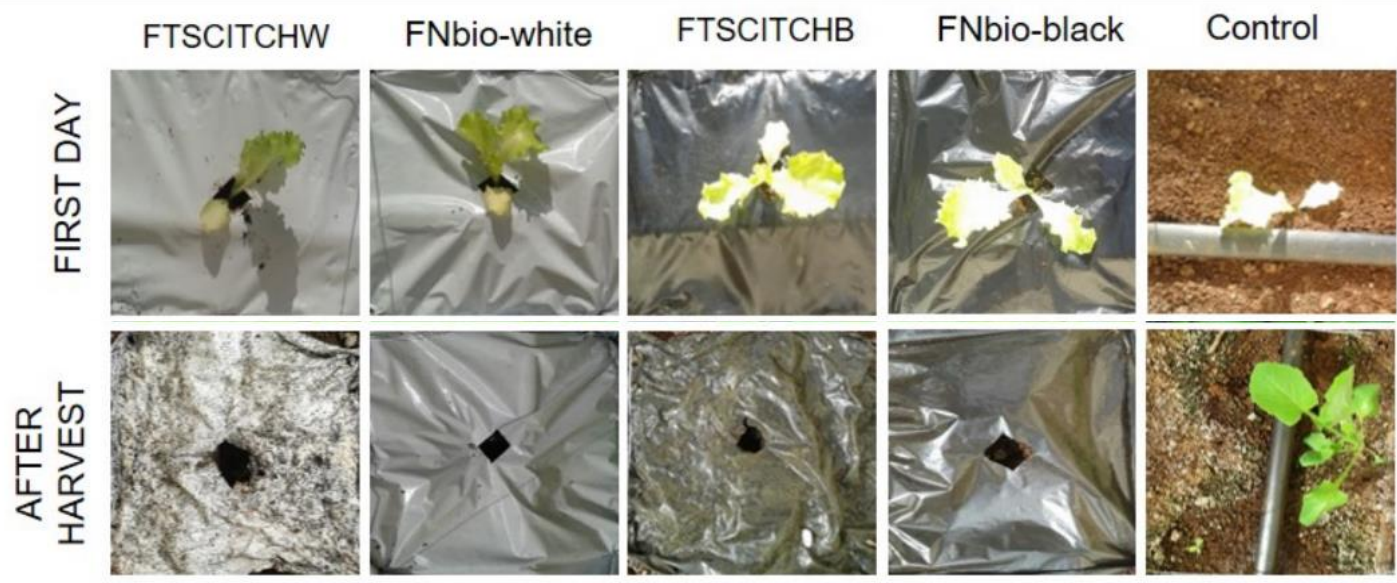

Figure 1. General appearance of the white (FTSCITCHW) and black (FTSCITCHB) biodegradable films in the first day, and immediately after harvest. FNbio-white and FNbio-black are films of polyethylene

\subsection{Spectroscopy of Infrared (FTIR)}

The Fourier transform IR (FTIR) analysis was carried out using a spectrometer (Spectrometer FTIR Cary 630, Agilent, Canada) coupled with a device that reduces the reflectance containing a crystal diamante/ZnSe with triple reflection (State University of the Campinas). The resolution of the spectra was $4 \mathrm{~cm}^{-1}$ in the range from 400 to $4001 \mathrm{~cm}^{-1}$. The samples were maintained in a desiccator containing calcium chloride for 15 days.

\subsection{Scanning Electron Microscopy}

Scanning electron microscopy (SEM; Hitachi TM 3030) was conducted at the Centre of Analysis at the Federal University of Technology - Paraná (Pato Branco, Brazil). The films were frozen in liquid nitrogen and fragmented. They were then maintained in a desiccator with $\mathrm{CaCl}_{2}$ for 15 days. The samples were glued to stubs and analyzed at an accelerating voltage of $15 \mathrm{kV}$. SEM observation was carried out by increasing the magnification to $600 x$.

\subsection{Isotherms of the sorption}

The isotherms of the sorption of the films were determined for different conditions of relative humidity $(11.8 \%, 32.8 \%, 43.2 \%, 52.9$ $\%, 64.5 \%$, and $90 \%$ ) at $25{ }^{\circ} \mathrm{C}$. The samples were cut to dimensions of $20 \times 20 \mathrm{~mm}$ and were dehydrated for 30 days in a desiccator containing the saturate solutions of the $\mathrm{CaCl}_{2}$. The films were weighed and conditioned in a recipient containing saturate solutions of salts with different relative humidities until 3 measures equal (condition of balance) in analytical balance were obtained. The absolute moisture (dry base) was determined by drying methods in a stove $\left(105^{\circ} \mathrm{C}\right.$ for $24 \mathrm{~h}$ ). All the tests were carried out in triplicate. The isotherms were modelled using the model of Guggenhein-Anderson-de Boer (GAB) conform equation 1 . The software Statistica 6.0 was used to model the parameters by the method of Quasi-Newton.:

$$
X_{w}=\frac{C \cdot k \cdot m_{o} \cdot a_{w}}{\left[\left(1-k \cdot a_{w}\right)\left(1-k \cdot a_{w}+C \cdot k \cdot a_{w}\right)\right]},
$$

where $C$ is the heat of sorption in the monolayer, $k$ is the heat of sorption in the multilayer, and $m_{o}$ is the monolayer value in $\mathrm{g}$ water/g solids, all of which are model 
parameters; $X_{\mathrm{w}}$ is the moisture in the dry base (g water/g solids) and $a_{w}$ is the relative moisture $(\mathrm{RH}) / 100$.

\subsection{Water Vapor Permeability (WVP)}

We used the gravimetric method to determine the permeability of the films to water vapor, in which 96-95 of the ASTM were adapted from the standard. ${ }^{12}$ The gradient of $\mathrm{RH}$ was maintained at $73 \%$. The levels of humidity used were $2 \%$ and $75 \%$. The WVP was calculated using:

$$
\mathrm{WVP}=\frac{t W V P \times \delta}{A \cdot P S(R H 1-R H 2 / 100)}
$$

Where $t W V P$ is the tax of permeability to the water vapor (g of water / day), $\delta$ is the middle thickness of the films, $A$ is the area of permeation of the capsule $\left(28,26 \times 10^{-4} \mathrm{~m}^{2}\right)$, $P s$ is the pressure of saturation of the water vapor to $25{ }^{\circ} \mathrm{C}(163,678,8)$, and $R H$ is the relative moisture inside the desiccator (subrate 1 ) and capsule (sub-rate 2 ).

\subsection{Solubility of the films}

The solubility of the films was analyzed in triplicate. First, the specimens were cut to 20 $\times 20 \mathrm{~mm}$. They were then dried in a stove at $105^{\circ} \mathrm{C}$ for $6 \mathrm{~h}$ and weighted to obtain the valor of the initial mass (P1). The samples were contained in bottles with $50 \mathrm{~mL}$ of distilled water ( $\mathrm{pH} 7.2)$; the bottles were transferred to a Dubnoff agitator at $25^{\circ} \mathrm{C}$ and were agitated to $100 \mathrm{rpm}$ for $8 \mathrm{~h}$, and the water was separated from the samples. The samples were dried in an oven at $105{ }^{\circ} \mathrm{C}$ for $6 \mathrm{~h}$; they were then weighted to obtain the non-soluble mass (P2). The solubility (\% S) was calculated using equation 3 .

$$
\% S=\frac{P_{1}-P_{2}}{P_{1}} \times 100
$$

\subsection{Mechanical property}

The mechanical properties were investigated in accordance with the standard D 882-88 of the ASTM. ${ }^{13}$ The resistance was analyzed as the tensile resistance at rupture (MPa) and elongation (\%). The traction properties were determined using a texturometer (TX2i, Stable Micro Systems, United Kingdom). The dimensions of the specimens were $100 \times 20 \mathrm{~mm}$, and were stipulated until the $\mathrm{RH}$ was balanced at $52.9 \%$. The specimens were placed between pneumatic hair clips, with the distance between the clips adjusted to $50 \mathrm{~mm}$, and the speed of traction was adjusted for $0.83 \mathrm{~mm} /$ $\mathrm{min}$. The tests were carried out at $25^{\circ} \mathrm{C}$. Four measurements were conducted for each sample.

\section{Results and Discussion}

\subsection{Isotherm of sorption}

The isotherms of sorption were obtained for the films and are presented in Figure 1, they were also adjusted to the model of GAB, the parameters of which are presented in Table 1. The isotherms determined for the starch/chitosan films presented aspect sigmoidal, similar to that obtained for other authors $(14,15)$, which is characteristic of products with high amounts of carbohydrates, presenting an expressive increase in the quantity of water sorption for a humidity relatively equal to or more than $70 \%$. 


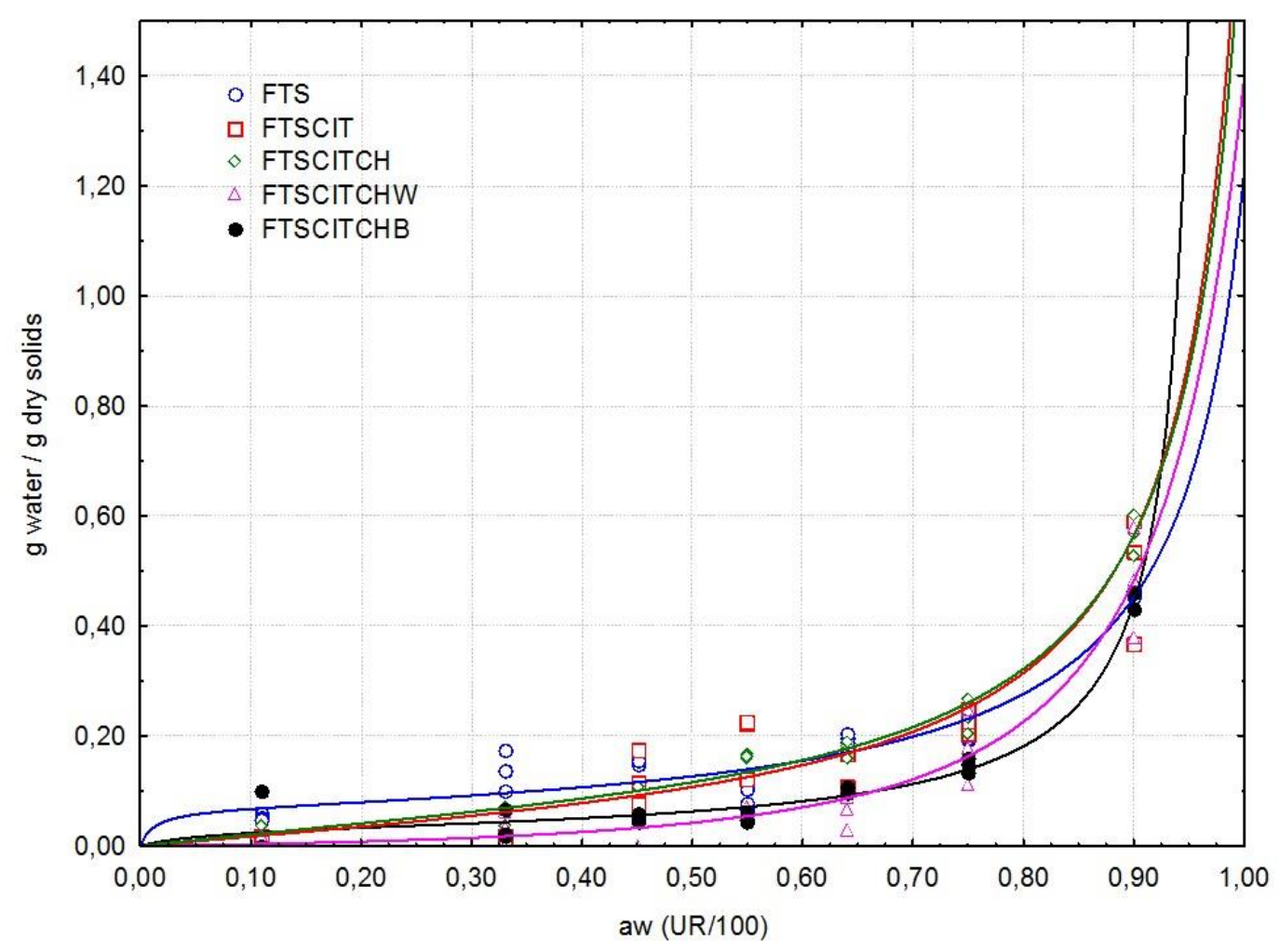

Figure 2. Isotherms of water vapor sorption obtained at $25^{\circ} \mathrm{C}$. FTS: films comprising $100 \%$ starch; FTSCIT: added films of citric acid; FTSCITCH: films of starch/chitosan; FTSCITCHW: white films of starch/chitosan; FTSCITCHB: black films of starch/chitosan

Figure 2 shows that small values of monolayer $\left(m_{o}\right)$ were obtained for pigment films, confirming that these films have less quantity of chemically associated water in their matrices, particularly in the black films. The films with $100 \%$ starch (FTS), with citric acid (FTSCIT), and with added chitosan (FTSCITCH) present similar $m_{0}$ values, according to the parameters presented in Table 1, indicating no reduction in the water adsorbed by the films with the addition of citric acid and chitosan. Similar $m_{o}$ values were reported by other researchers ${ }^{1,14,15}$ for starch and chitosan films, confirming that the presence of chitosan does not reduce the hydrophilicity of starch films.
The white starch-chitosan films (FTSCITCHW) presented $m_{o}$ values similar to those of the pure starch films (FTS)), while the black starchchitosan films (FTSCITCHB) presented twotimes less $m_{o}$ values. A similar behavior was observed for the starch/chitosan films when they were added to the black pigment of the iron (III) oxide nanoparticles. ${ }^{4}$ According to this report, films with $2 \%$ pigment-to-iron ratio presented lower absorption capacity and swelling in acidic environment, due to the interactions between the iron ion and the hydroxyl groups of the polymer chains, reducing the availability of water for the films. For the black films, the reduction in the intensity of the bands corresponding the $\mathrm{OH}$ groups in the IR spectra confirm the previous result (Figure 2). 
Table 1. Parameters of the Guggenheim-Anderson-de Boer (GAB) model obtained for starch and chitosan films under isothermal conditions $\left(25^{\circ} \mathrm{C}\right)$

\begin{tabular}{lcccc}
\hline Films & $\begin{array}{c}{ }^{\text {a) }} \mathbf{m} \text { ( } \begin{array}{c}\text { (g water/g dry } \\
\text { solids) }\end{array} \\
\text { FTS }\end{array}{ }^{\text {a) }} \mathbf{C}$ & ${ }^{a)} \mathbf{k}$ & $\mathbf{R}^{\mathbf{2}}$ \\
FTSCIT & 0.070 & 83.93 & 0.95 & 0.94 \\
FTSCITCH & 0.080 & 2.37 & 0.94 & 0.93 \\
FTSCITCHB & 0.080 & 2.16 & 0.96 & 0.98 \\
FTSCITCHW & 0.032 & 16.74 & 1.03 & 0.98 \\
\hline
\end{tabular}

a) Parameters determined for the GAB model. $C$ is the heat of sorption in the multilayers, $m_{\circ}$ is monolayer and $k$ is the constant of sorption of the water (steam) in the multilayers, and $R$ is the coefficient of regression

\subsection{Spectroscopy of the films for FTIR}

The spectra of the analyzed films are presented in Figure 3. The spectra were similar for starch films with and without added citric acid (FTSCIT and FTS, respectively), indicating that the citric acid did not form crosslinks with the chemical groups of the starch under the conditions used to prepare the films. Reddy and Yang ${ }^{7}$ reported that when citric acid was added to the starch films, the spectra showed a band at $1724 \mathrm{~cm}^{-1}$, corresponding to the association between the carboxylate and hydroxyl groups. However, in this work, there were no relevant changes in the spectra of these films.

The starch-chitosan pigment film (FTSCITCH) present very different spectra from those determined for starch films (FTS) or starch-citric acid films (FTSCIT). The differences in the spectra are, firstly, due to the presence of the characteristic chemical groups of chitosan: bands at $3300 \mathrm{~cm}^{-1}$ owing to $\mathrm{OH}$ group stretching, at $2900 \mathrm{~cm}^{-1}$ owing to $\mathrm{CH}_{2}$ group stretching, at $1660 \mathrm{~cm}^{-1}$ due to the presence of water, at $1559 \mathrm{~cm}^{-1}$ band due to the protonated amine group (amine II) stretching, and at 1386 and $1367 \mathrm{~cm}^{-1}$ due to the $\mathrm{CH}$ group stretching. However, there was a reduction in the intensity of the $\mathrm{OH}$ stretching band at $3300 \mathrm{~cm}^{-1}$ for films with chitosan, especially with the addition of black pigments (Figure 3). Another important difference is the change in the band corresponding to the glyosidic ring from 1660 $\mathrm{cm}^{-1}$ for the starch-only films to $1638 \mathrm{~cm}^{-1}$ for the starch-chitosan films, indicating that chemical association occurred between the starch and chitosan. Similar dislocation of the bands at $1640 \mathrm{~cm}^{-1}$ was observed, due to the configuration alterations of the glycosidic ring via association of the chitosan groups with starch. ${ }^{16}$ 


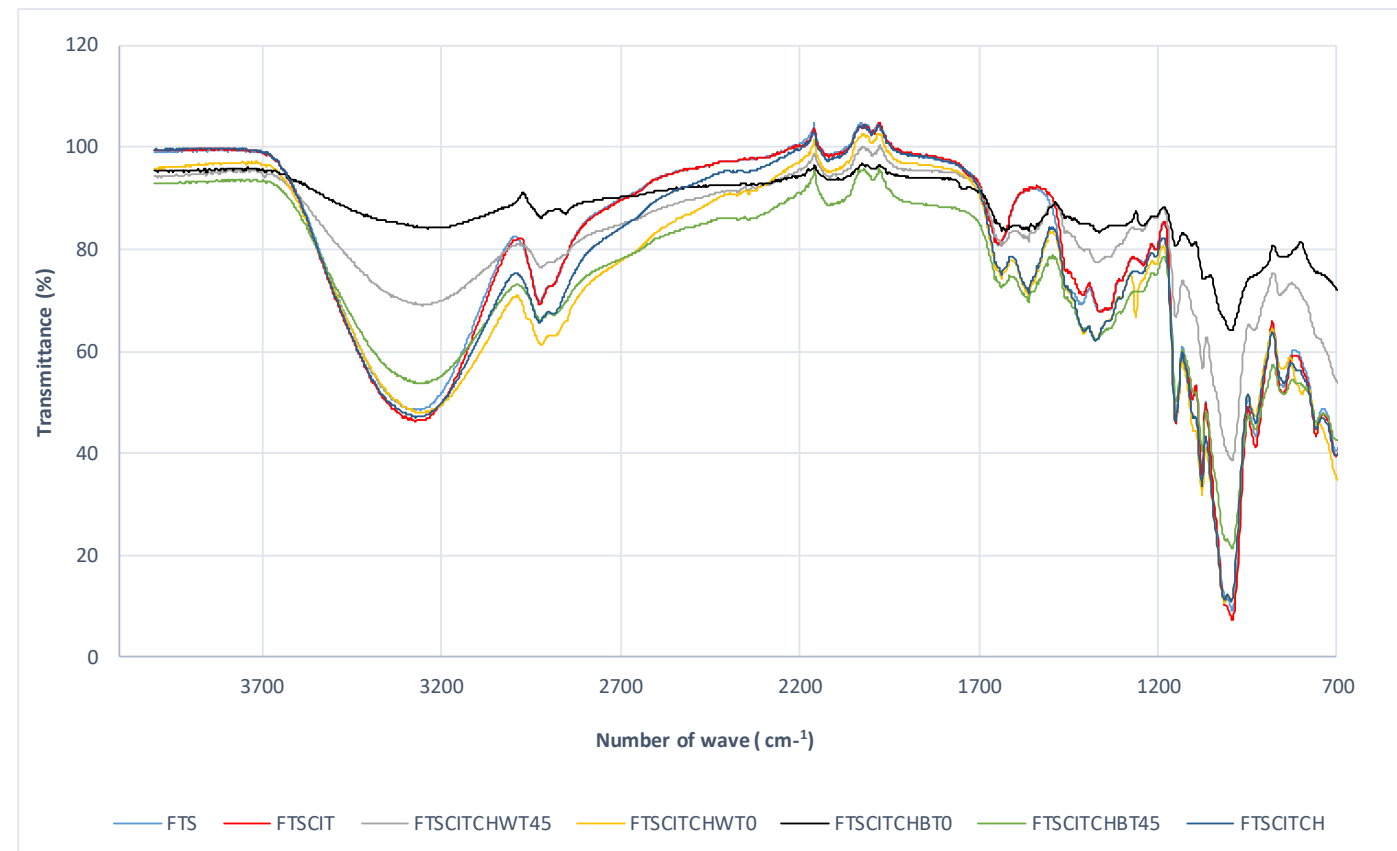

Figure 3. IR spectrum of the white starch/chitosan films (FTSCITCHW), after 45 days of contact with the soil (FTSCITCHW45), that of the black starch/chitosan films (FTSCITCHB), and again after 45 days of contact with the soil (FTSCITCHB45), for starch/chitosan films without pigments (FTSCITCH), as well as for films only comprising starch (FTS), and starch with added citric acid (FTSCIT)

The addition of white pigments in starch films and chitosan (FTSCITCHW) did not alter the spectra of the films compared to those (FTSCITCH) without pigments; only at 1297 $\mathrm{cm}^{-1}$ the white films deferred of too many films. Meanwhile, the addition of black pigments (FTSCITCHB) altered the intensity of the band at $3300 \mathrm{~cm}^{-1}$, corresponding to $\mathrm{OH}^{-}$ stretching, indicating that there were associations between starch and the components of the black pigment; the $\mathrm{Fe}^{2+}$ ions possibly formed linkages with the hydroxyl groups of the starch. The $m_{0}$ values obtained for the FTSCITCHP films reinforce the association between the starch and the $\mathrm{Fe}^{2+}$ ions. Shariatinia and Fazli ${ }^{4}$ found the same behavior for the spectra of starch films with pigments containing iron ions.

The spectra of the films FTSCITCHB45 and FTSCITCHW45 correspond to those of the black or white starch/chitosan films that remained for 45 days on the growing soil. The spectra presented the same directions for both the black (FTSCITCHB) and white (FTSCITCHW) films before contacting with the soil however, the intensities of all the bands reduced drastically in the films that remained for 45 days on the soil, indicating that the films were degraded by the action of the microorganisms that caused quantitative reduction of the chemical substances comprising the films.

\subsection{Microscopy of the films}

The microscopy images of the starch and chitosan films with and without pigments (Figure 4) show that all the films presented compact microstructures without structural damages, like pores, fractures, or separated phases. Other researchers have determined similar microstructures, indicating that there is excellent compatibility between starch and chitosan. ${ }^{14}$ The starch/chitosan films with added black pigments were more compact, as can be observed in Figure 4, than those without pigments or with added white pigments, indicating that the polymer chains 
were most aligned in the presence of the black pigment.

The alterations of the black films reinforce the formation of the interactions between the $\mathrm{OH}$ groups of the polymers and the iron ions, conforming with the IR spectra of these films. Similarly, Shariatinia and Fazli ${ }^{4}$ reported which starch/chitosan films presented improvements in the properties when iron oxide nanoparticles were added to the starch/chitosan films.

The SEM micrographs of the black (FTSCITCHB45) and white (FTSCITCHW45) starch/chitosan films in contact with the soil show structural alterations in the films characterized by the presence of pores, indicating structural damage caused by the action of soil microorganisms.
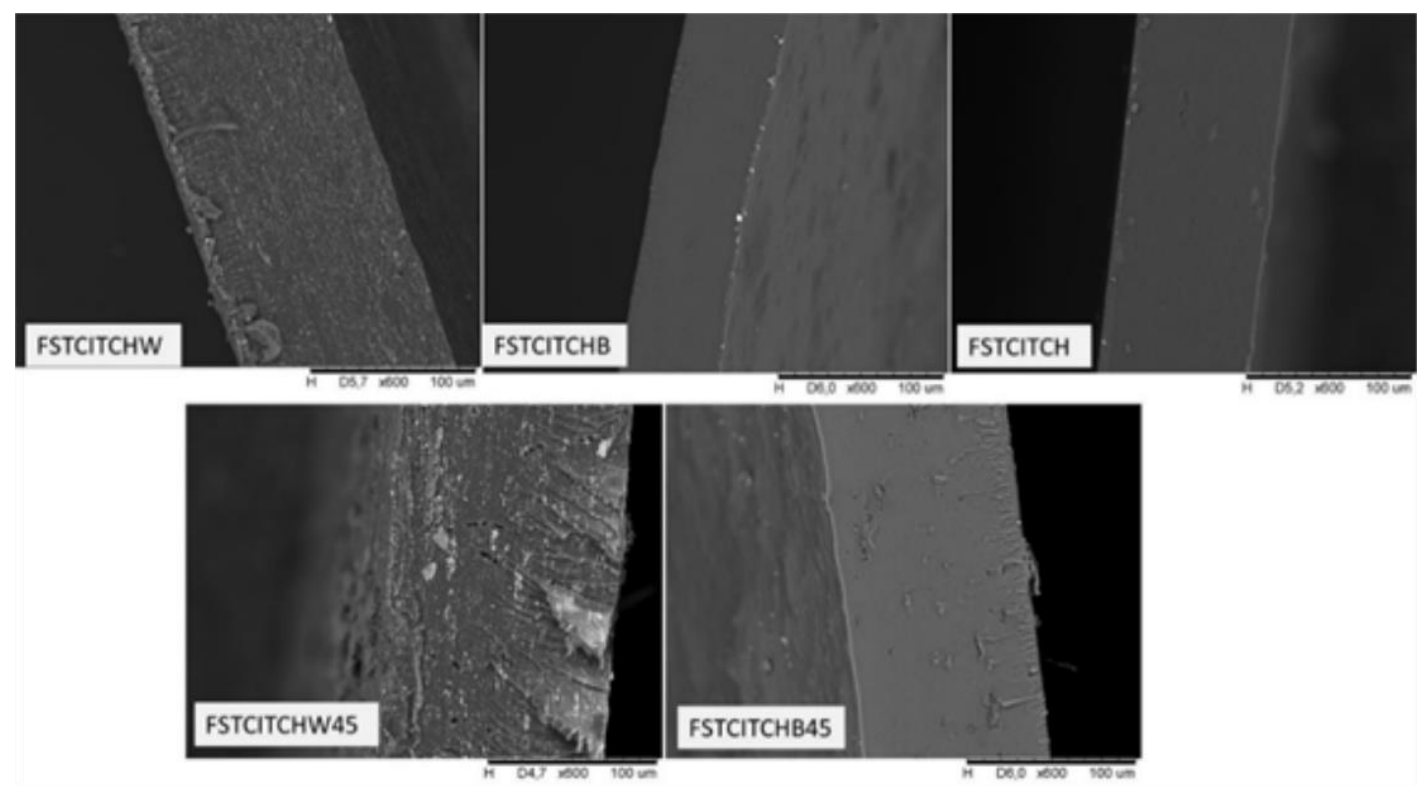

Figure 4. SEM micrographs of the starch/chitosan films without the addition of pigments (FSTCITCH), with white pigment before and after contact with the soil (FSTCITCHW and FSTCITCHW45, respectively), and with black pigment before and after contact with the soil (FSTCITCHP and FSTCITCHP45, respectively) at an increased magnification of 600x

3.4. Thickness, mechanical properties, permeability to water steam, and solubility

The thicknesses of the films are listed in Table 2; it can be seen that film thickness varied with formulation. The films with chitosan were thicker than those with $100 \%$ starch or starch with citric acid. The polymer mass for the specific plate area was the same for all the films; therefore, the difference in thickness can be associated with the capacity of the polymeric solution in spread on plate; therefore, by increasing the viscosity of the solution cam increase the thickness. The obtained starch and chitosan films presented similar behavior. ${ }^{4}$ According to the authors, chitosan increases water sorption more than starch because of the amine groups present in the polymer molecule; these groups increase the free volume between the polymeric chains, thereby increasing thickness. The thickness of the films of starch/chitosan did not vary, indicating that the addition of citric acid or pigments did not affect thickness (Table 2). 
Table 2. Thickness, mechanical properties, and water vapor permeability of the films

\begin{tabular}{lccccc}
\hline Films & $\begin{array}{c}\text { Thickness } \\
(\mathrm{mm})\end{array}$ & $\begin{array}{c}\text { Tensile } \\
\text { strength } \\
(\mathrm{MPa})\end{array}$ & $\begin{array}{c}\text { 三longation } \\
(\%)\end{array}$ & $\begin{array}{c}\times 10^{-13} \mathrm{WVP} \\
\left(\mathrm{g} \cdot \mathrm{s}^{-1} \cdot \mathrm{Pa}^{-1} \cdot \mathrm{m}^{-1}\right)\end{array}$ & $\begin{array}{c}\text { Solubility } \\
(\%)\end{array}$ \\
\hline FTS & $0.075^{\mathrm{c}}$ & $7.21^{\mathrm{b}}$ & $39.21^{\text {to }}$ & $9.20^{\text {ns }}$ & $36.95^{\text {to }}$ \\
FTSCIT & $0.092^{\mathrm{bc}}$ & $6.72^{\mathrm{b}}$ & $27.01^{\mathrm{b}}$ & $6.22^{\mathrm{ns}}$ & $29.75^{\text {to }}$ \\
FTSCITCH & $0.119^{\mathrm{ab}}$ & $9.60^{\mathrm{ab}}$ & $11.90^{\mathrm{b}}$ & $5.06^{\mathrm{ns}}$ & $18.70^{\mathrm{b}}$ \\
FTSCITCHB & $0.127^{\text {to }}$ & $10.40^{\mathrm{ab}}$ & $39.58^{\text {to }}$ & $10.08^{\text {ns }}$ & $18.15^{\mathrm{b}}$ \\
FTSCITCHW & $0.136^{\text {to }}$ & $13.74^{\mathrm{b}}$ & $41.22^{\text {to }}$ & $6.77^{\text {ns }}$ & $17.10^{\mathrm{b}}$ \\
FTSCITCHB45 & 0.185 & 4.43 & 1.28 & - & 7.26 \\
FTSCITCHW45 & 0.182 & 1.70 & 12,87 & - & 8.50 \\
\hline
\end{tabular}

Values in the columns followed by differ superscripted letters indicate that have the averages significant differ by Test of the Tukey at $95 \%$ of probability. Values followed by "ns" indicate that not have difference in the averages

The films that remained in contact with the soil exhibited increased thickness, possibly due to the presence of the soil and other residues. The variation of the starch/chitosan film masses was also evaluated by weighing the film samples before soil application and after 45 days; it was observed that film masses increased after 45 days (values not presented). Liu et $a l^{18}$ determined that starch/cellulose composites rapidly degrade within 3 weeks; however, their samples were buried $8-10 \mathrm{~cm}$ under the soil surface. In contrast, in this study, the films were placed above the soil, thereby reducing degradation velocity. Therefore, if buried in the soil, the films would show the highest degradation velocity because of increased contact with soil microorganisms. From Figure 1, mold adhesion can be seen on the film surface, which was not removed even after washing the films in water. Therefore, the thickness and the variation of the film mass were not suitable parameters to characterize the degradation of the starch/chitosan films over the soil surface.

The maximum tensile strength at rupture did not vary with the addition of chitosan, citric acid, or pigments (Table 2) to the films; and the tensile strength values remained between 7.21 and $13.74 \mathrm{MPa}$. The values of resistance determined in this work were lower than those reported by Xu et al. ${ }^{16}$ for films of starch/chitosan ( 25 to $40 \mathrm{MPa}$ ) and higher than those by Basiak el al. ${ }^{14}$ for films of $100 \%$ starch (3.72 MPa). The FTS and FTSCIT films did not show significant alterations in resistance, and the FTSCIT films were less elastic than those containing $100 \%$ starch. These contradicting results were observed by Reddy and Yang ${ }^{7}$ when the resistance of starch films with additional citric acid increased by 10 for $20 \mathrm{MPa}$.

The elongation of the films varied between $11.9 \%$ to $40.22 \%$ (Table 2), which is characteristic of rigid films. However, lower values were reported for films containing 100 $\%$ starch. The elongation was low $(<p=0,05)$ for films without pigments. $\mathrm{Xu}$ et al. ${ }^{17}$ determined the nonlinear relationship between film elongation and starch-chitosan proportion.

The starch/chitosan films, when exposed to the soil, exhibited a reduction in their resistance by at least $57 \%$ with the addition of black pigments and approximately $90 \%$ with the addition of white pigments. The elongation also reduced by more than $60 \%$ for the films in contact with the soil, i.e., for those 
associated with microbial degradation. The same behavior was reported by Kijchavenjkul et al., ${ }^{11}$ who demonstrated that starch films with PBAT poly(butylene adipate-coterephthalate) became rigid or fragile when exposed to the soil. Although the objective of this study is not to evaluate the biodegradability of the films, the diminished mechanical properties are indicative of the increasing degradability of the films when in contact with soil microorganisms. The inferior properties, according to Figure 1 and Figure 3, of the films without the presence of pores and cracks till 45 days, indicate that the alterations made the films fragile.

The WVP values varied from 5.06 to 10.08 $\times 10^{-13} \mathrm{~g} \cdot \mathrm{s}^{-1} \cdot \mathrm{Pa}^{-1} \cdot \mathrm{m}^{-1}$. The water permeability of the films did not differ with the addition of chitosan, citric acid, or pigments $(p>0.05)$. It was reported that WVP reduced with the addition of $5 \%$ citric acid in starch films; however, the values obtained in these studies were the highest. ${ }^{7,19}$ The WVP of the films in contact with the soil could not be determined because of mold growth after exposure to 75 $\%$ moisture for 8 days, thereby hindering the analysis of the films under the conditions identical to those wherein the films did not contact the soil.

The addition of chitosan caused a two-fold reduction in solubility of starch films. Chitosan is a cationic polymer and insoluble in water, but soluble in acid solutions; thus, when chitosan replaced the same amount of starch, the obtained films were least soluble in water. ${ }^{20,21}$ Similar results were reported for starch films and chitosan. ${ }^{1,5}$ The reduction in solubility can be achieved only for specific quantities of chitosan; when added in high proportions, film solubility is not reduced. ${ }^{6,8}$ The films that were in contact with the soil exhibited less solubility, because the polymer mass decreased, thereby reducing the number of sites for the formation of linkages with water. The spectroscopic results of the films in contact with the soil confirmed that the intensity the band corresponding to the hydroxyl group reduced.

\section{Conclusion}

The properties of the films of starch and chitosan with the addition of citric acid and pigments were characterized. The addition of citric acid to starch did not alter the properties of the films prepared under the studied conditions. The addition of chitosan to the films was important to reduce film solubility in water. FTIR spectra confirmed the alteration and dislocation of bands when chitosan and black pigments were added to the films. The monolayer values indicated that black films of starch/chitosan were less hydrophilic. Moreover, the addition of black or white pigments to the films improved flexibility. The properties of black starch/chitosan films were superior to those of pure films containing starch and without pigments.

Based on the FTIR spectra, the films were found to be degradable for a long period; however, the films were maintained intact over the soil for 45 days. The inferior mechanical properties and solubility confirmed that the films degraded although visual analysis did not indicate presence of cracks or pores on the film surface. The results suggest that the starch/chitosan films have potential for applications such as biodegradable mulching for short cycle vegetables and flower crops, which can be investigated in the future achieving for beneficial, fertilizer-free and microbialculture-based plant growth.

\section{References}

${ }^{1}$ Pelissari, F. M.; Yamashita, F.; Grossmann, M. V. E. Extrusion parameters related to starch/chitosan active films properties. International Journal of Food Science and Technology 2011, 46, 702. [CrossRef]

${ }^{2}$ Quiroz-Castilho, J. M., Rodríguez-Félix, E., Grijalva-Monteverde, H., Lizárraga-Laborin, L. L., Castilho-Ortega, M. M., Castilho-Castro, T del, Rodríguez-Félix, F., Herrera-Franco, J. Preparation and Characterization of Films 
Extruded of Polyethylene/Chitosan Modified with Poly(lactic acid). Materials 2015, 8, 137. [CrossRef]

${ }^{3}$ Ohta, K., Taniguchi, A, Konishi, N., Hosok, T. Chitosan Treatment Affects Plant Growth and Flower Quality in Eustoma grandiflorum. Hortscience 1999, 34, 233. [CrossRef]

${ }^{4}$ Shariatinia, Z.; Fazli, M. Mechanical properties and antibacterial activities of novel nanobiocomposite films of chitosan and starch. Food Hydrocolloids 2015, 46, 112. [CrossRef]

${ }^{5}$ Bourtoom, T.; Chinnan, M. S. LWT Preparation and properties of rice starchchitosan blend biodegradable film. LWT-Food Science and Technology 2008, 41, 1633. [CrossRef]

${ }^{6}$ Ren, L.; Yan, X.; Zhou, J.; Tong, J.; South, X. Influence of chitosan concentration on mechanical and barrier properties of corn starch/chitosan films. International journal of biological macromolecules 2017, 105, 1636. [CrossRef]

${ }^{7}$ Reddy, N; Yang, Y. Citric acid cross linking of starch films. Food Chemistry 2010, 118, 702. [CrossRef]

${ }^{8}$ Yoon, S. D.; Chough, S. H.; Park, H. R. Effects of additives with different functional groups on the physical properties of starch/PVA blend film. Journal of Applied polymer 2006, 100, 2554. [CrossRef]

${ }^{9}$ Menzel, C.; Olsson, E.; Plivelic, T. S.; Andersson, P.; Johansson, C.; Kuktaite, R.; Jürnström, L.; Koch, K. Molecular structure of citric acid cross-linked starch films. Carbohydrate Polymers 2013, 96, 270. [CrossRef] [PubMed].

${ }^{10}$ Bilck, A. P.; Grossmann, M. V. E.; Yamashita, F. Biodegradable mulch-film for strawberry production. Polymer Testing 2010, 29, 471. [CrossRef]

${ }^{11}$ Kijchavengkul, T.; Zephyrs, R.; Rubino, M.; Ngouajio, M.; Fernandez, T. Assessment of aliphatic-aromatic copolyester biodegradable mulch films. Part I: Field study. Chemosphere 2008, 71, 942. [CrossRef]

${ }^{12}$ American Society will be Testing and Materials (ASTM). Standard test methods will be water steam transmission of material ASTM - E 96-95, Philadelphia: ASTM, 1995 [Link]

${ }^{13}$ American Society will be Testing and Materials (ASTM). Standard test methods will be tensile properties of thin plastic sheeting ASTM -D 882-18, Philadelphia: ASTM, 1996. [Link]

${ }^{14}$ Basiak, E.; Lenart, A.; Debeaufort, F. Effect of starch type on the physic-chemical properties of edible films. International Journal of Biological Macromolecules 2017, 98, 348. [CrossRef].

${ }^{15}$ Leceta, I.; Arana, P.; Gerrero, P.; la Caba K. Structure- moisture sorption relation in chitosan thin films. Materials Letters 2014, 128, 125. [CrossRef]

${ }^{16}$ Singh, N.; Maitra, J. Antibacterial Evaluation of Starch and Chitosan Based Polymeric Blend. Journal of Applied Chemistry 2015, 8, 26. [Link] ${ }^{17}$ Xu, Y. X.; Kim, K. M; Hanna, M. A. Nag, D. Chitosan-Starch Composite Film: Preparation and Characterization Industrialist Crops and Products 2005, 21, 185. [CrossRef]

${ }^{18}$ Liu, J.; Jiang, H.; Chen, L Grafting of Glycidyl Methacrylate onto Poly(lactide) and Properties of PLA/Starch Blends Compatibilized by the Grafted Copolymer. Journal of Polymers and the Environment 2012, 20, 810. [CrossRef]

${ }^{19}$ Seliagra, P. G.; Jaramillo, C. M.; Famá, L.; Goyanes, S. Biodegradable and nonretrogradable eco-films based on starchglycerol with citric acid as crosslinking agent. Carbohydrate Polymers 2016, 138, 66. [CrossRef]

${ }^{20}$ Chouljenko, A.; Chotiko, A.; Reyes, V.; Alfaro, L.; Liu, C.; Dzandu, B.; Sathivet, S. Application of water-soluble chitosan to shrimp for quality retention. Food Science and Technology 2016, 74. 571. [CrossRef]

${ }^{21}$ Furike, T.; Komoto, D.; Hashimoto, H.; Tamura, $\mathrm{H}$. Preparation of chitosan hydrogel and its solubility in organic acids. Journal of Biological Macromolecules 2017, 104, 1620. [CrossRef] 